\title{
CONSIDERAÇÕES EXTEMPORÂNEAS: JOAN MIRÓ, JOÃO CABRAL E MURILO MENDES
}

\section{Susana Scramim*}

\begin{abstract}
Resumo: Este ensaio tem por objetivo evidenciar as relações entre as teorias de arte moderna e as obras de três artistas, a partir das considerações que eles escrevem a respeito de questões de sua "atualidade”. Pensada a partir de práticas da arte primitiva, essa relação será abordada tanto na obra do pintor catalão Joan Miró quanto na poesia de João Cabral de Melo Neto e Murilo Mendes. Conceitos que necessariamente não seriam tomados como "modernos" na arte, são valorizados e assumidos como produtores de uma prática artística que inclui, naquilo que a modernidade designou como objetos estéticos, as formas "estetizantes" da vida prosaica.
\end{abstract}

Palavras-chave: Joan Miró. João Cabral de Melo Neto. Murilo Mendes. Modernidade. Arcaico.

JOAN MIRÓ POR JOÃO CABRAL: MODERNIDADE E EXTEMPORANEIDADE

É possível entrever a relação entre a obra de um poeta e a modernidade nas considerações que ele escreve a respeito de questões de sua "atualidade". O ensaio que João Cabral de Melo Neto escreveu sobre a obra de Joan Miró, de 1950, é o segundo texto em prosa do poeta pernambucano sobre seus contemporâneos. A lista de textos em prosa de João Cabral não é tão extensa, desde seu "Considerações sobre um poeta dormindo", de 1941; passando por "Poesia e composição", "A geração de 45", ambos datados de 1952; "Esboço de um Panorama", de 1953; "Como a Europa vê a América", "Da função moderna da poesia", ambos de 1954; "Elogio a Assis Chateaubriand", de 1969; até o "A diversidade cultural no diálogo Norte-Sul", de 1990, o que caracteriza a relação do poeta Cabral com o seu presente é a extemporaneidade, ou seja, o que define sua posição é o seu ponto de vista estranho à época e aos valores nela dominantes, capaz por isso de suscitar uma relação crítica ao criar um distanciamento em relação a esses mesmos valores. Foi com um ponto de vista extemporâneo que Friedrich Nietzsche escreveu os quatro ensaios que compuseram a série Considerações extemporâneas na qual ele elabora uma crítica à cultura alemã de sua época. Os ensaios levaram os títulos de "Wagner em Bayreuth", "David Strauss, o devoto e o escritor", ambos de 1873, e "Da utilidade e desvantagem da história para a vida" e "Schopenhauer educador", de 1874, e pensaram a modernidade sob uma perspectiva alheia a sua própria época.

A obra de Joan Miró desempenhou o mesmo papel, para João Cabral de Melo Neto, que a obra de Richard Wagner, em seu empreendimento na construção do teatro em Bayreuth e na reformulação da relação entre música e linguagem verbal para a

\footnotetext{
* Doutora em Letras (Teoria Literária e Literatura Comparada) pela Universidade de São Paulo e professora de Teoria Literária da Universidade Federal de Santa Catarina. E-mail: susana@cfh.ufsc.br.
} 
compreensão da obra de arte moderna, teve para Nietzsche. Wagner, para o filósofo alemão, alterou a relação com seu público, incluindo na obra elementos de que o espectador necessitaria para produzir experiências compartilháveis. O princípio que elege para tal é ultrapassar a fronteira entre campos artísticos, mesclar suas regras. Wagner teria feito o caminho inverso ao imposto pela modernidade a suas obras, ou seja, o de especializar e separar os campos artísticos em unidades autônomas. De certa maneira, Wagner estaria retomando um princípio arcaico na composição da obra moderna.

Para João Cabral de Melo Neto, Miró teria introduzido na sua pintura um princípio de luta contra a ordem estática do quadro do mesmo modo que os pintores do Renascimento teriam criado a terceira dimensão com o intuito de incluir no quadro um elemento dinâmico. A pergunta enunciada pelo texto de Cabral é a de se haveria um outro procedimento de composição, que não o do ponto de fuga, que devolvesse à superfície o seu sentido antigo, isto é, o de ser o receptáculo do dinâmico. Cabral busca a eficácia de um movimento que inserisse objeto/sujeito na ambiência da paisagem inscrevendo-se ali para dissolver-se em um ritmo dado pela tonalidade dessa mesma ambiência. Trata-se de liberar esse ritmo na composição que o equilíbrio introduzido pelo Renascimento aprisionou em nome de uma presença muito intelectual do objeto/sujeito que foi desenvolvida, cito Cabral:

[...] à custa da utilização sensorial da superfície. Porque o aperfeiçoamento na representação do objeto terminaria por passar do desejo de obter a ilusão do relevo desse mesmo objeto já lograda, aliás, anteriormente pelo Renascimento - ao desejo de obter a ilusão do ambiente em que ele se situava. Isto é, a pintura desenvolveu-se em outra dimensão. Em profundidade (o que é mais do que relevo) (MELO NETO, 2003, p. 692).

À liberação desse ritmo da ambiência Cabral nomeia de terceira dimensão, cujo efeito mais visível é o de anular a existência do dinâmico - riqueza da pintura antiga -. A pintura de Miró aboliria a terceira dimensão com o intuito de seguir buscando o "dinamismo" na obra, tornando-a receptáculo de um ritmo interno. Isso pareceria contraditório se nesse dinamismo não estivesse pressuposto a rasura do limite da composição. João Cabral destaca que há na obra de Miró:

\footnotetext{
... - a partir do momento em que aboliu de sua pintura a terceira dimensão - um caminho. Mas esse caminho tem um sentido: Miró, colocado diante da superfície, começou a fazer, em sentido inverso, o caminho que a superfície havia percorrido até que pudesse conter aquela terceira dimensão imaginária. [...] talvez ele tenha sido o primeiro a compreender que o tratamento da superfície como superfície libertava o pintor de todo um conceito de composição.

É contra o conceito limitado de compor (compor como equilibrar) que Miró empreende então sua luta obscura (MELO NETO, 2003, p. 695-696).
}

Lutar de modo obscuro contra um conceito de compor pensado como equilíbrio, contra uma concepção de movimento pensado como harmonia é o modo com o qual João Cabral de Melo Neto compreende a revolução estética operada pelo trabalho de Miró, é o modo como qual Cabral compreende a extemporaneidade de atualidade do trabalho de Miró. Trata-se, contudo, de uma revolução estética que mantém relação vital com as 
práticas de revolução social, uma vez que alterar o modo de percepção de uma obra de arte - justamente da maneira operada pela arte de Miró - é alterar a percepção do mundo ao seu redor. Quando se toma o conceito de dinamismo no âmbito da modernidade não se pode negligenciar o seu sentido imediato de movimento e de produção de movimento, uma vez que a concepção de temporalidade é histórica e não mitológica. Tomado como valor intrínseco à ideia e motivação do moderno, a valorização do movimento, do agir e, por consequência, da desvalorização de tudo o que é estático não coaduna com a proposição moderna de "produção" e "circulação". Mesmo em teóricos e artistas marxistas a ideia de movimento e ação foi e é extremamente preconizada como elemento de valor no âmbito da obra. Ao questionar a ideia da terceira dimensão como promotor do movimento e da ação dentro da obra de arte, no caso de Miró, o sentido do dentro do quadro, o artista oferece destaque a algo que não está previsto no regime de percepção daquela obra pensada a partir da terceira dimensão como obra moderna. Isso quer dizer que o moderno nessa obra passa a ser definido por algo que é estranho a essa mesma modernidade. Com isso, esses elementos não modernos que estão ali funcionando e sendo constituídos como modernos transformam a percepção, a sensação e interpretação da arte moderna ao acolherem no seu ambiente aquilo que parecia oposto à ideia de arte moderna. Ao fragmentar o ponto de vista, uma vez que Miró para Cabral não suprime totalmente a ideia de ordenação do sentido sob um ponto de vista, o pintor destrói a ideia de um sentido único no quadro. Trata-se de ser e não ser moderno, pois se a ideia de ordenação e o movimento estão presentes, no entanto, não são realizados a partir de uma unificação em direção a um sentido.

\footnotetext{
Pouco interessado em equilibrar, em fixar, as experiências que Miró realiza nessa época parecem buscar uma medida fora daquela medida fatal, por meio da qual se obtém o equilíbrio sólido e não ameaçado da pintura nascida no Renascimento. Nessa época, ainda distante do dinamismo posterior, o que Miró explora não é um ato temporal do espectador. É mais bem uma forma de energia, até então não descoberta: a que pode advir da colocação de uma figura numa posição tal, dentro da superfície, que produz no espectador uma sensação de que ela vai precipitar, mudar de lugar.

Essa energia, evidentemente, é uma ilusão. A um olho não automatizado, não acostumado inconscientemente às proporções e ao equilíbrio que se adquirem na contemplação de museus e reproduções, ou melhor, a um olho selvagem, virgem dessa forma com as quais o hábito visual amoldou nossa contemplação, essa energia é imperceptível. Sempre que não se dê a tendência espontânea de todo olho, de colocar a coisa onde se acostumou a ver as coisas colocadas, essa energia, essa sensação de coisa que se precipita e quer buscar sua própria estabilidade, será imperceptível (MELO NETO, 2003, p. 698).
}

Miró cria um tipo de máquina ótica na qual se inscrevem objetos que não são arte, mas que justamente por estarem inscritos nessa máquina se transformam em uma constelação em movimento na qual se formam os modos de percepção, os afetos e formas de interpretação que definem o paradigma de arte. Trata-se de uma cena, de uma quase teatralização da linguagem da pintura na qual são apreendidos conceitos em ação, portanto, as cores ou as linhas não são senão conceitos em ação na sua relação com novos objetos dos quais as cores e linhas procuram apropriar-se para pensá-los novamente. Se a arte moderna é a conquista da autonomia no âmbito de cada uma das artes, na pintura de Miró, segundo João Cabral, nega-se a autonomia expressa em obras exemplares, em 
pontos de vista específicos e coerentes com um sentido unificado e unidirecional, e que se constituem como uma ruptura com o movimento evolutivo de certa concepção de história. Se a arte moderna se apresenta segundo os pressupostos de conquista, ordenação e evolução, corta os laços e relações com arte do passado porque ali não encontrou a autonomia estética. Como consequência dessa posição não se reconhecem os problemas do moderno como sobrevivências do arcaico, apregoando-se a separação definitiva das formas "estetizantes" da vida prosaica. A pintura de Miró apresenta-se como uma história da modernidade ao revés: uma metamorfose do antigo de que se nutre o moderno. A retomada da superfície em detrimento da noção de um único ponto de vista no quadro é produto de uma consciência artística que se volta para o inconsciente coletivo, diga-se também, volta-se para o primitivo, uma vez que os objetos que se intenciona apresentar na cena da pintura não cessam de não se inscreverem, já que se anulam na sintaxe espacial na qual estão colocados e não alcançam independência de sentido, ou seja, estão "autoimplicados" desde seu momento de inscrição no texto.

À semelhança do drama musical de Wagner, por exemplo, no Anel de Nibelungo, o destino do personagem Wotan expressa a operação própria da música moderna, ou seja, a caída dos deuses no silêncio, no qual as ideias de movimento e de ação são tomadas como princípio de inação, como meio para introduzir-se numa nova linguagem musical e nisso constituindo-se a sua força de crítica à impotência a que a obra moderna está sujeita quando toma para si a tarefa inconclusiva de criar o espaço próprio para sua música - arte da coletividade por excelência -; a obra de Miró, pensada por Cabral, empreende a tarefa de deslocar-se à espacialidade superficial do objeto visto no ambiente em que ele se inscreve de um outro modo que não o previsto na construção do ponto de fuga - marca da linguagem unívoca do sujeito - dentro do quadro. Miró ultrapassa o limite do quadro, e cria uma outra espacialidade para seus objetos os quais podem, desde logo, sair dos limites do marco. O artista Miró de Cabral não busca a música, contudo, o pensamento musical de Wagner buscava o encontro com a potência infinita da linguagem, o poder de comunicar-se sem palavras; Miró reintroduz-se no espaço anódino dos objetos sem relevo com a finalidade de reencontrar sua "energia" comunicativa. Ambos, Wagner e Miró, empenham toda essa aventura para construir uma espécie de língua nova, plena na sua potência de dizer, em face à impotência da arte moderna em transmitir experiências pela ação de um homem livre ou de um corpo bem ordenado capazes de atuar com objetivo sobre o curso repetitivo da vida dos homens comuns. Trata-se de trazer de volta a vida mesma do poema e não a intenção do poeta que acontece quando a forma perceptiva de sua própria arte renuncia a si mesma.

Quando analisa algumas das montagens da peça de Ibsen, $O$ mestre Solness, Jacques Rancière associará a necessidade de se reinventar o espaço cenográfico para abrigar o "ambiente" não ativo das peças do dramaturgo norueguês à aproximação nos dramas musicais de Wagner da música ao silêncio, que o que nos faz retornar à ideia de espaço-tempo e linguagem criados fora da lógica da representação. Sobre a montagem de o Anel de Nibelungo observa que:

\footnotetext{
A música não intervém para ilustrar o destino de Wotan. É, antes de tudo, a história desse personagem a que expressa a operação da própria música. Que o mesmo pensamento da música convenha aos silêncios de um drama falado e ao conteúdo de um drama musical não
} 
é coisa de metáfora aproximada. Esse deslocamento do conceito nos lembra que uma arte sempre é mais do que uma arte, mais que a reunião de modos específicos de ordenar a palavras, os sons, as cores, os volumes ou os movimentos. É uma ideia da música como ideia da arte nova. A música já não é somente a arte dos sons harmoniosos, é a expressão do mundo anterior à representação (RANCIÈRE, 2011, p. 156) ${ }^{1}$.

Não é outra coisa o que João Cabra de Melo Neto observa na arte de Miró:

Na curta conversa de Miró, uma palavra existe: vivo, a meu ver muito instrutiva. Vivo é o adjetivo que ele emprega, mais do que para julgar, para cortar qualquer incursão ao plano do teórico, onde jamais se sente à vontade. Vivo parece valer ora como sinônimo de novo, ora de bom. Em todo caso, expressão de qualidade. Essa palavra a meu ver indica bem o que busca sua sensibilidade e, por ela, sua pintura. Essa sensação de vivo é o que existe de mais oposto à sensação de harmônico ou de equilibrado. Ela nos é dada precisamente pelo que sai desse harmônico ou desse equilibrado, diante do qual nossa sensibilidade não se sente ferida, mas adormecida.

É a esse vivo que parece aspirar a pintura de Miró. Isto é, a algo elaborado nessa dolorosa atitude de luta conta o hábito e a algo que vá, por sua vez, romper, no espectador, a dura crosta de sua sensibilidade acostumada, para atingi-la nessa região onde se refugia o melhor de si mesma: sua capacidade de saborear o inédito, o não-aprendido (MELO NETO, 2003, p. 718).

E é também de modo muito semelhante que a obra de Miró iria chamar a atenção de Michel Leiris e Georges Bataille, que analisam sua obra alguns anos antes que João Cabral de Melo Neto, contudo, o que organiza suas análises, inclusive a de Cabral, é, como foi demonstrado aqui, a inflexão nietzschiana da obra de Miró de crítica ao modelo estético moderno no qual o discurso é tomado como um corpo de membros bem ajustados, o poema como uma história e a história como ordenamento de ações num tempo linear. Essa ordem alinha claramente a arte a um modelo hierárquico no qual o alcance do poder de mando é sua meta principal.

Em 1947, Michel Leiris, em "Sobre Joan Miró", ressalta a ligação com elementos telúricos na pintura do catalão, associados especialmente à temporalidade de tempo presente. É a partir desse modo de operar que deriva a cena montada em suas telas nas quais se pode entrever um outro ordenamento do mundo materializado num tipo de "surrealismo camponês, ligado à terra" (2015, p.33). Georges Bataille, em Documents 2, n. 7 (1930), na resenha que escreve sobre o livro de G. H. Luquet, L'art primitif (1930), desenvolve a sua teoria da arte primitiva como produção do informe e a relaciona com a arte de vanguarda contra-revolucionária, anti-moderna, portanto, derivada da análise nietzschiana da modernidade. Após o texto da resenha de Bataille seguem reproduzidas nas páginas de revista, como suplemento ao texto, seis Pinturas, todas de 1930, de Miró, sob o título de "Joan Miró, peintures récentes": Peinture (1930) 230x160, Peinture (1930)

\footnotetext{
${ }^{1}$ Tradução própria. A seguir, cita-se o texto da fonte: “La Musique n’pas lá pour illustrer le destin de Wotan. C'est bien plutôt l'histoire de ce personnage que exprime l'opération propre de la musique. Que la même pensé de la musique convienne aux silences d'un drama parlé et au contunu d'un drame musical n'est pas affaire de méthafore approximative. Ce bougé du concept nous rappelle qu'un art est toujours plus qu'un art, plus que la reunión de moyens spécifique d'ordonner la parole, les sons, les coulours, les volumes ou les mouvements. Il est une idée de ce que fait l'art. La révolution wagnérienne ne fonde pas simplement une nouvelle manière de faire de la musique mais une idée de la musique comme idée de l'art nouveau. La musique n'est pas plus seulement l'art des sons harmonieux, elle est l'expression du monde d'avant la représentation".
} 
150x225, Peinture (1930) 133x230, Peinture (1930) 150x225, Peinture (1930) 230x165, Peinture (1930) 235x155, indicando a relação que Bataille empreende entre primitivo e moderno, isto é, a sobrevivência do mundo arcaico na arte moderna.

\section{JOÃO CABRAL DE MELO NETO E MURILO MENDES: A POESIA DE JOAN MIRÓ}

Murilo Mendes em Tempo Espanhol escreve:

Joan Miró

Soltas a sigla, o pássaro e o losango.

Também sabes deixar em liberdade

O roxo, qualquer azul e o vermelho.

Todas as cores podem aproximar-se

Quando um menino as conduz no sol

E cria a fosforescência:

A ordem que se desintegra

Forma outra ordem ajuntada

Ao real - este obscuro mito

(MENDES, 1995 [1955-1958], p. 618).

Esse poema está incluído numa série de poemas cujos objetos são quadros pintados. O poema "Joan Miró" parece estar olhando para a pintura em óleo Figur vor Roter Sonne, do pintor catalão. E o destaque que o poema de Murilo Mendes lhe oferece é o da desordem que forma uma outra ordem que não suprime a desordem anterior as quais convivem simultaneamente. A ordenação proposta pela modernidade artística não suprime o arcaico - não linearmente ordenado - do mito.

Figura 1. Joan Miró, Figur vor Roter Sonne, 1950.

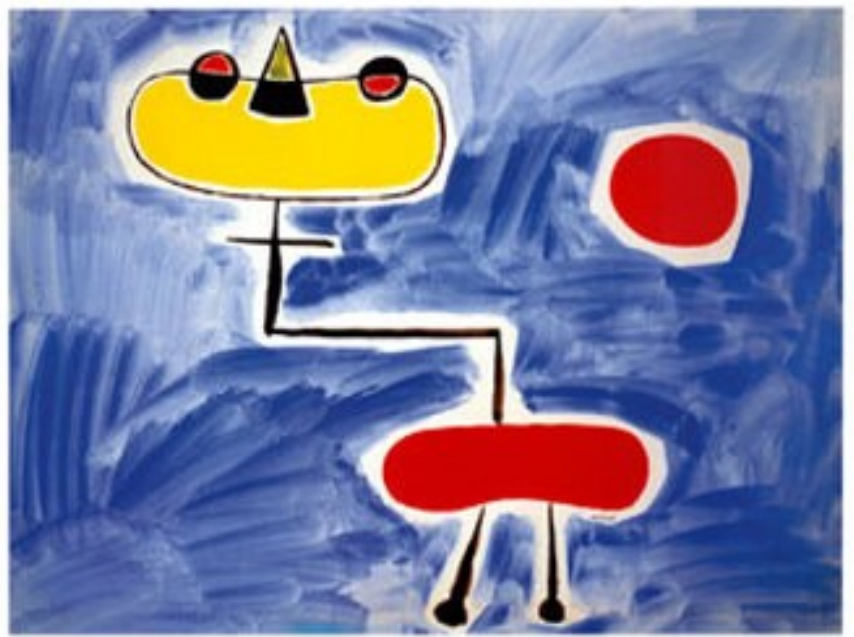


A galeria de quadro-poemas é extensa nessa seção de Tempo Espanhol. O referido poema é antecedido pelo "Crianças de Tarragona", "Juan Gris", "Picasso", e sucedido por "Guernica", "O padre Cego" e "Morte situada na Espanha". Todos com fortes indícios de quadros ante os quais os poemas se posicionam.

O poema "Crianças de Tarragona" é outro poema a "homenagear" o pintor catalão. Além de ultrapassar o olhar convencional sobre a pintura de Miró, no qual são sempre elencadas as figuras da mulher, pássaro, estrela, sol, lua e terra, o destaque para uma existência infantil no quadro aponta para um modo específico de olhar, ou de olhar para um outro lugar, do próprio poema de Murilo Mendes.

\author{
Crianças de Tarragona \\ Crianças de Tarragona \\ Sitiam a cidade pétrea \\ Cerrada nas suas muralhas \\ E na catedral compacta. \\ Crianças de Tarragona \\ Brincando no sol de ferro \\ Conduzem a força de Espanha \\ Que a tudo imprime caráter. \\ Crianças de Tarragona \\ Mostrando nos olhos férteis \\ A gana do amor e vida \\ Que nutre o sangue da Espanha. \\ Crianças de Tarragona \\ Já do enigma carregadas, \\ Guardareis sempre a influência \\ Do solo e pedra compactos \\ (MENDES, 1995 [1955-1958], p. 617).
}

Observe-se que são as crianças os agentes dentro do texto e suas ações são os resultados do enigma do qual estão carregadas. Enigma e modernidade no poema não estão convivendo em lugares distintos, estão, sim, coabitando o mesmo espaço-tempo. As imagens no poema são impressionantes: crianças sitiam a cidade pétrea; crianças brincam no sol de ferro e imprimem caráter; crianças com seus olhos férteis nutrem o sangue; crianças guardiãs da influência da natureza. Murilo Mendes dedicou o poema "Crianças de Tarragona" a Alfonso Pintó, organizador e responsável pela edição de Cobra Norato, de Raul Bopp, e ilustrada por Joan Miró, publicada pelo grupo Dau al set, grupo surrealista catalão ao qual esteve vinculado João Cabral de Melo Neto. 
Figuras 2 e 3. Cobra Norato, de Raul Bopp. Ilustrações de Joan Miró, 1954.

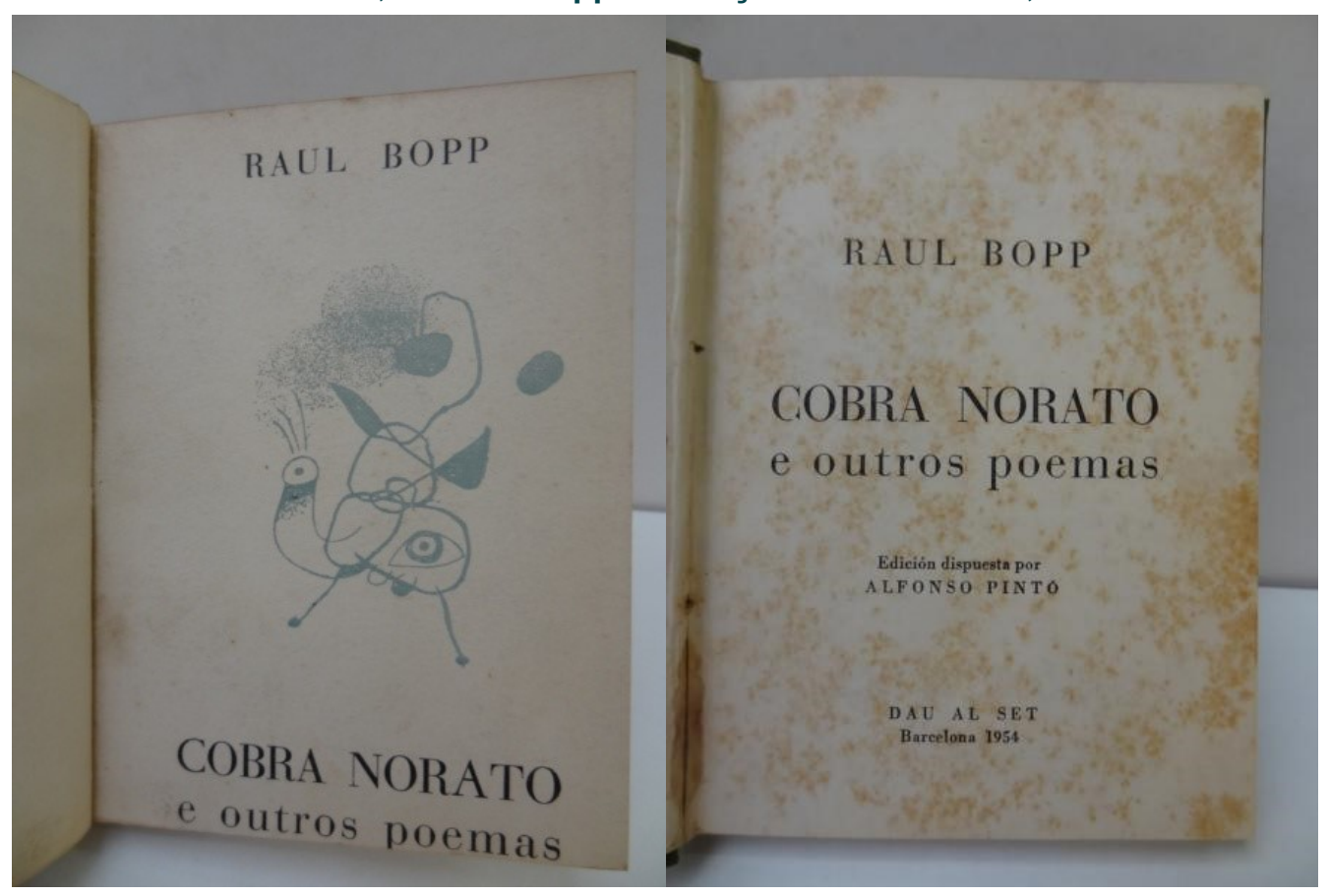

No livro Paisagens com figuras (1954-1955), de João Cabral de Melo Neto, há um poema intitulado "Campo de Tarragona", note-se a contemporaneidade com o poema de Murilo Mendes, "Crianças de Tarragona", e o ponto de vista extemporâneo de ambos frente à modernidade de Joan Miró e de suas próprias obras poéticas.

\author{
Campo de Tarragona \\ Do alto da torre quadrada \\ da casa de En Joan Miró \\ o campo de Tarragona \\ é mapa de uma só cor. \\ É a terra de Catalunha \\ terra de verdes antigos, \\ penteada de avelã, \\ Oliveiras, vinha, trigo
}

\begin{abstract}
No campo de Tarragona dá-se em guardar desvãos: como planta de engenheiro ou sala de cirurgião.
\end{abstract}

\author{
No Campo de Tarragona \\ (campo ou mapa o que se vê?) \\ a face da Catalunha \\ é mais clássica de ler.
}


Podeis decifrar as vilas, constelação matemática, que o sol vai acendendo por sobre o verde de mapa.

Podeis lê-las na planície como em carta geográfica, com seus volumes que ao sol têm agudeza de lâmina.

podeis vê-las, recortadas, com as torres oitavadas de suas igrejas pardas, igrejas, mas calculadas.

Girando-se sobre o mapa, desdobrando pelo chão ao pé da torre quadrada, se avista o mar catalão.

É mar também sem mistério, é mar de medidas ondas, a prolongar o humanismo do campo de Tarragona.

Foram águas tão lavradas quanto os campos catalães. Mas poucas velas trabalham, hoje, mar de tantas cãs

(MELO NETO, 2003, p. 154-155).

A relação entre campo e mapa, entre território político e natureza, entre mar e humanismo marca a relação do poema com seu objeto: Miró. Com isso, o poema deixa ver não somente a ambiência da obra de Miró na sua relação com a modernidade, mas também a ambiência do poema e da obra do poeta que o escreve. Trata-se de uma modernidade com outro ordenamento. Essas questões estavam relacionadas ao trabalho de Miró mesmo antes de ele ter desenvolvido um caminho surrealista em sua pintura. Na pintura Montroig, la iglesia y el pueblo, de 1918, já se pode entrever a relação entre ordenamento e desordem natural promovida por um ponto de vista arcaico na montagem da cena. 
Figura 4. Joan Miró, Montroig, la iglesia y el pueblo, 1918.

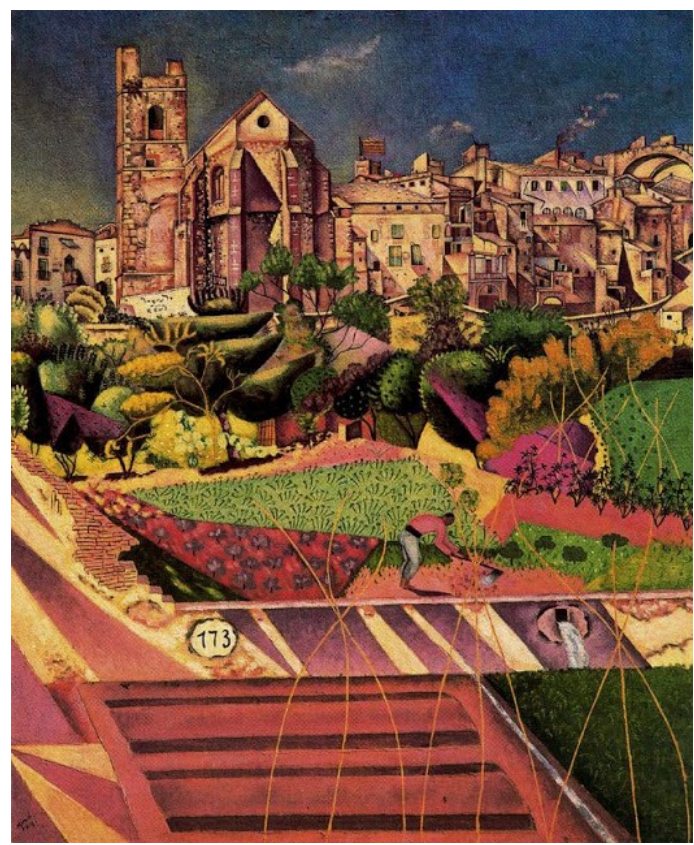

O mesmo se pode observar no quadro La masia:

Figura 5. Joan Miró, La masía, 1922.

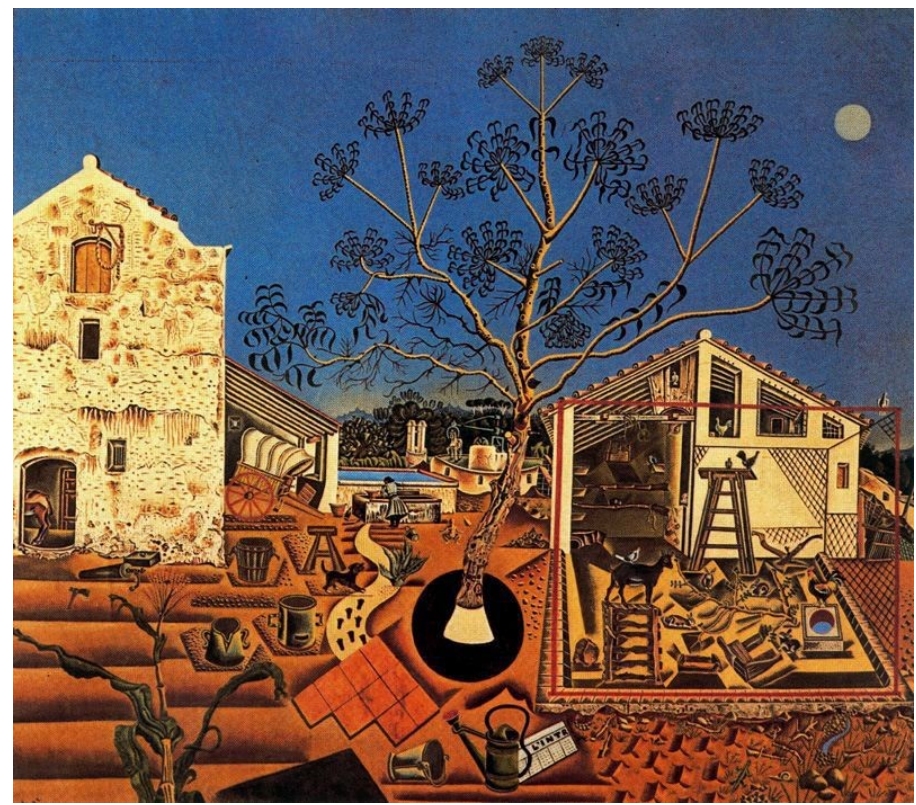

Aqui, modernidade - conquista do espaço, ordenamento, cálculo, divisão e potência - entram em conjunção com os elementos que advêm do arcaico, ou seja, as forças e formas da natureza não dominada - sol, céu, secura da vegetação, aridez do solo - fazem parte da montagem dos diversos pontos de fuga da cena. Esses quadros estão em relação direta com o ponto de vista e as imagens construídas nos poemas de Murilo Mendes e João Cabral de Nelo Neto. Na segunda série dos seus Retratos-Relâmpagos, Murilo 
Mendes volta a tratar do problema da arte de Joan Miró. E destaca, já em sua primeira impressão, da arte do catalão sua vocação para pensar o moderno com o método arcaico:

- Miró declara que não pode separar a poesia da pintura. Rompe a linha convencional do
discurso, criando a sigla, o número plástico, a alusão.
- Exorciza o lado mecânico de nosso tempo. Organizando a infância futura, consegue, em
todos os casos, conciliar sonho e disciplina racional. [...]
- Miró extrai o maravilhoso da coisa imediata, visível; transforma em realidade a faixa
onírica. (MENDES, 1995 [1975-1976], p. 1275).

Murilo Mendes, antes dessa tentativa de compor o retrato de Joan Miró, já tinha criado uma espécie de imagem do pintor catalão e sua pintura. Trata-se do relato alegórico incluído no livro Espaço Espanhol (1966-1969), intitulado “Joan Prats". Nele se ressalta a figura de um trabalhador extemporâneo ao tempo moderno, um artífice, um homem que faz chapéus masculinos, e tem loja aberta na "Rambla de Cataluña". O texto ressalta a extemporaneidade da confecção e do uso do chapéu já na sua circunstância.

\begin{abstract}
Não sou suficientemente vaidoso para pretender-me o último homem a usar chapéu. Tenho colegas dispersos por esse "mundo, vasto mundo". Felizmente: do contrário me sentiria abandonado e só, quem sabe um maníaco, um doido, um dinossauro. Cada vez que columbro um homem enchapeuzado alegro-me, conforto-me; sorrio-lhe discretamente: pertencemos a uma sociedade ligada por laços invisíveis, embora com fins mais restritos que a Maçonaria (MENDES, 1995, p. 1171).
\end{abstract}

Quando entra em contato pessoal com o Señor Prats, o autor descobre uma loja organizada aos moldes antigos, um estúdio de artífice que Joan herdara de seu avô. E qual não foi sua surpresa ao ver que esse homem antigo e de modos e gostos antigos - no texto constata-se que o estúdio estava adornado com gravuras do século XIX, documentando os usos do chapéu desde muito antes - colecionava desenhos de Joan Miró em meio a toda essa atmosfera do arcaico.

\footnotetext{
Com efeito o chapeleiro, de longa data amigo do pintor (nascido e durante muito tempo vivido em Barcelona) possui um grande número de obras compradas na fonte. A coleção começa aqui, mas a parte fundamental conserva-se na sua casa, aonde sou depois conduzido pelo dono, que me desvenda suas riquezas: uns 50 Mirós divididos por todas as peças. $\mathrm{Na}$ coleção figuram quadros representativos dos primeiros períodos do pintor. É mesmo o caso de se tirar o chapéu, mais ainda a Joan Prats do que a Miró. (MENDES, 1995, p. 1172).
}

A conjunção entre o arcaico e o moderno que Murilo Mendes opera nesse breve relato sobre mais um elemento da paisagem cultural de Barcelona demonstra, uma vez mais, sua concepção de modernidade, ou seja, uma coexistência entre espaço e tempo díspares os quais, nessa conjunção, não se organizam de modo antagônico. 
BATAILLE, Georges. "L 'art primitif". Documents 2. Doctrines. Archéologie, Beaux-Arts, Ethnographie, no 7, Paris, out. 1930, p. 389-397.

LEIRIS, Michel. "Sobre Joan Miró” [1947; 1970]. Revista Serrote, n 19, Instituto Moreira Salles, São Paulo, p.31-43, março de 2015.

MELO NETO, João Cabral. Poesia Completa. Rio de Janeiro: Nova Aguilar, 2003.

MENDES, Murilo. Poesia Completa e Prosa. Rio de Janeiro: Nova Aguilar, 1995.

NIETZSCHE, Friedrich. Wagner em Bayreuth. Tradução de Anna Hartmann Cavalcanti. Rio de Janeiro: Ed. Zahar, 2009.

RANCIÈRE, Jacques. Aisthesis. Scènes du régime esthétique de l'art. Paris: Galilée, 2011.

Recebido em 10/09/16. Aprovado em 12/11/2016

Title: Extemporaneous considerations: Joan Miró, João Cabral and Murilo Mendes

Abstract: This essay proposes to evidence the relations between modern art theories and the considerations that the three artists wrote about questions of the present. Reflected after primitive art practices, this relation will be addressed either in Catalan painter Joan Miró as in João Cabral de Melo Neto and Murilo Mendes poetries. Concepts that not necessarily are considered as "moderns" in art are valorized and assumed as producers of an artistic pratice that includes, in that which modernity designed as aesthetics objects, the aestheticizing forms of prosaic life.

Keywords: Joan Miró. João Cabral de Melo Neto. Murilo Mendes. Modernity. Archaic.

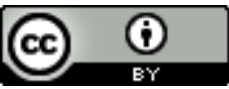

Este texto está licenciado com uma Licença Creative Commons Atribuição 4.0 Internacional. 